\title{
Partial Weaning at Six Weeks of Age Reduces Biting among Mink Kits (Neovison Vison)
}

\author{
Tove Nørgaard Clausen, Peter Foged Larsen \\ Kopenhagen Research, Kopenhagen Fur, Aarhus, Denmark \\ Email: peter.foged.larsen@gmail.com
}

Received 6 February 2015; accepted 10 March 2015; published 16 March 2015

Copyright (C) 2015 by authors and Scientific Research Publishing Inc.

This work is licensed under the Creative Commons Attribution International License (CC BY). http://creativecommons.org/licenses/by/4.0/

c) (7) Open Access

\begin{abstract}
Recent studies have demonstrated that postponed weaning age from 6 weeks to 8 weeks in mink increases the number of bites among mink kits. Therefore, a series of studies have been conducted in order to quantify effects of weaning age on mortality, number of bites and growth rates in mink kits weaned at 42 and 56 days after birth during two consecutive breeding seasons. Partial weaning of large litters on Day 42 reduced the number of mink kits and litters with bites from an average frequency of $1.6 \%$ to $1.0 \%$ for kits and $8.1 \%$ to $5.1 \%$ for litters and increased growth rate of male kits. These results are highly important for ensuring optimal welfare in mink production, and we recommend that partial weaning (dividing) of large litters should be considered in practical mink farming in the future.
\end{abstract}

\section{Keywords}

Age of Weaning, Bites, Mortality, Growth Rate

\section{Introduction}

In recent years, focus on animal welfare has resulted in legislation in relation to weaning of mink kits in practice. New recommendations were implemented in 2006, resulting in a weaning age of mink kits at eight weeks (56 days) as a compromise on the welfare for both dam and kits [1]. This practice, although well intended, may have contributed to increased biting among some kits, jeopardizing their welfare.

Biting among mink kits in a litter is mainly observed between six and eight weeks of age. Bites inflicted on the kit while alive can be distinguished from those after death, during autopsy [2] [3]. Based on autopsy analysis of bite marks, Reference [4] separated dead kits into those killed by either the dam or siblings, and those that died of other causes. Kits bitten after death from other causes are most often seen from early June to July, corresponding to kit age of 30 - 60 days, whereas kits bitten by siblings occur most frequently from mid-June to 
early-July (kit age 44 to 68 days) [2]. Therefore, it appears that when the mink kits have started to eat mink feed, and the female's milk production is decreasing and stopping (around 6 weeks after birth), there will be increased problems with bites among siblings [2]. Whether this occurrence results from resource competition for feed, dominance among the kits or presence of the female is currently unknown; however, litter size appears to have a substantial effect [5].

According to Danish legislation, mink kits are not allowed to be weaned before 8 weeks (56 days of age), unless the welfare of the female or kits is at risk. However, there are studies suggesting that these 8 weeks may not be optimal for the welfare of the female [6] and the kits [5]. Reference [7] had reported that most bites on brown mink kits occurred from Days 42 to 49 (0.4\% of kits) with only $0.1 \%$ of the kits displaying bites between Days 49 and 56. There was a significant difference in the number of bites among weeks but not among the two groups (weaning age 49 and 56 days) and apparently the impact of the female was of less importance in this period [5]. This suggests that it is resource competition or fighting for dominance that triggers the biting among mink kits.

Reference [4] reported that kits weaned on Day 42 exhibited reduced growth rates and increased mortality between Days 42 and 49, when compared with kits weaned on Day 49 or 56. While these findings may appear to suggest that weaning should be delayed until after Day 42, it is noteworthy that the increased mortality and reduced growth rates are observed for the smallest kits in larger litter sizes. In agreement with these findings, others [3] [5] [7] reported that most biting occurred in the larger litters, and that $65 \%-80 \%$ of the bitten kits were females. Therefore, our objective was to determine the effects of a weaning program where the largest kits in large litters (6 - 9 kits) were removed first (Day 42 of age) followed later (Day 56) by complete weaning, on frequency of biting, growth rate and mortality.

\section{Materials and Methods}

Mink were housed in typical two rows outdoor mink houses according to Danish legislations, and the experimental setup was approved under the animal permit at the Research Farm by the Animal Testing Control. The animals received commercial mink feed (Holstebro Feed Kitchen, Holstebro) and water ad libitum. Feed intake per female and kits increased from 680 grams (950 kcal) on Day 42 to 990 grams (1525 kcal) on Day 56.

\subsection{Experimental Design}

Partial weaning of mink kits on Day 42 of age was compared with the current practice of weaning of kits on Day 56 , to determine their effects on biting among kits and growth rates. Studies were conducted over two consecutive breeding seasons (2012 and 2013), resulting in the analysis of 1361 large litters (6 - 9 kits/litter). In 2012, 386 litters were partially weaned on Day 42, and 408 litters weaned on day 56 (Table 1). In 2013, 298 litters were partially weaned on Day 42, and the remainder (269) on Day 56 (Table 1). Partial weaning was accomplished by removing the biggest kits (approximately an equal number of males and females) from each litter on Day 42 and housing them 4 - 5 together, while the remaining kits stayed with the dam until Day 56 (Table 2). Complete weaning involved following standard farm practices in Denmark, by removing all kits on Day 56 of age. All large litters (6 - 9 kits) resulting from matings during 2012 (794) and 2013 (567), were randomly assigned to two groups; one group to be partially weaned on Day 42, and the other to be weaned on Day 56.

\subsection{Animals}

Live kits were counted on Days 42 and 56. All kits were examined for bites every day and all kits in bitten litters

Table 1. Experimental setup: number of litters divided and undivided in 2012 and 2013, litter size in the groups and sex distribution among groups.

\begin{tabular}{ccccc}
\hline Year & & Number of litters & Litter size & Percent male/female kits \\
\hline 2012 & Undivided (control) & 408 & 7.7 & $79.7 / 50.3$ \\
& Divided & 386 & $50.3 / 49.7$ & 7.6 \\
2013 & Undivided (control) & 269 & $51.8 / 48.2$ & 7.7 \\
\hline
\end{tabular}


Table 2. Number of kits removed from each litter (housed alone) and those that remained with the dam.

\begin{tabular}{ccc}
\hline Litter size & Kits removed (alone) & Kits with dam \\
\hline 6 & 4 & 2 \\
7 & 4 & 3 \\
8 & 5 & 3 \\
9 & 5 & 4 \\
\hline
\end{tabular}

were weighed individually when found. Bites were categorized as neck, ear and "other" (head, shoulder, body and tail). Only bites that penetrated the dermis of the skin were recorded and then subsequently treated. Therefore, fur chewing and similar non-invasive activities are not included in this study. To evaluate the effects of partial weaning on kit weight gain, we randomly selected 214 litters in 2012 and weighed all kits on Days 42 and 56.

\subsection{Statistical Analysis}

To the statistical analyses, we used the SAS PROC MIXED, FREQ and PROBIT procedures [8]. The models included day of birth and age of female as general fixed effects. The number of degrees of freedom was estimated by using Kenward-Rogers's approximation. Differences between groups were considered significant at P $<0.05$.

\section{Results}

\subsection{Mortality and Bites among Kits in Experimental Groups}

The total number of kits that died, during both breeding seasons, in undivided litters between Days 42 and 56 was 120 (2.1\% of all kits) compared to $93(1.8 \%)$ kits that died from litters partially weaned on Day 42 . There was no difference between the number of male (110) and female (103) kits that died during this time. During the 2012 breeding season, 21 out of 6113 kits $(0.34 \%)$ died as a result of biting.

On Day 56, there was a higher number of kits with bites from undivided litters $(\mathrm{n}=85,1.6 \%)$ when compared to litters divided on Day $42(\mathrm{n}=54,1.0 \%$; Table 3$)$. Moreover, the number of litters with bitten kits from undivided litters $(55,8.1 \%)$ was greater, when compared to divided litters $(35,5.1 \%$ : $\mathrm{P}<0.05$, Table 3$)$. In litters with bitten kits, on average 1.55 kits were bitten in the litter (data not shown). Average litter size and sex distribution among male and female kits were identical among groups (Table 3 ).

\subsection{Location of Bites}

A total of 96 kits (31 males and 65 females) exhibited bites on the neck (34, 26\%), ear (25, 26\%) and "other" (37, 39\%, Table 4). Over twice as many females (68\%) had bites when compared to males (32\%). The majority of bites on male kits were ear $(68 \%)$, with only $6 \%$ of females having similar bites. Females were bitten mostly on the neck $(49 \%)$ or "other" locations $(45 \%)$.

\subsection{Growth Rates on Experimental Groups}

Higher growth rates were observed for male mink kits from the divided litters compared to male kits from the undivided litters. On Day 42 the mink kits placed "alone" on average weighed more than the other two groups. This was expected, because these kits were chosen as the largest in the litter, and therefore placed "alone". On Day 56 only male mink kits in the "divided-alone" group weighed more than the other two groups. Higher growth rates were observed for both groups of divided litters - either "with female" or "alone" - compared to the undivided control litters (Table 5). Mean body weights of bitten female kits $(451+8.9)$ were lower $(\mathrm{P}=$ $0.0007)$ when compared to those of unbitten sisters within litters $(475+7.0)$ on the day of biting. In contrast, body weights of bitten male kits $(553+26.2)$, did not differ $(\mathrm{P}=0.4)$ from those of unbitten brothers $(529+11.1)$ within litters. 
Table 3. Number of kits and litters with bites, average litter size and percent male/female for divided and undivided litters.

\begin{tabular}{ccccc}
\hline Group & $\begin{array}{c}\text { Number of kits with bites/total } \\
\text { number of kits (\% with bites) }\end{array}$ & $\begin{array}{c}\text { Number of litters with bites/total } \\
\text { number of litters (\% with bites) }\end{array}$ & $\begin{array}{c}\text { Average litter } \\
\text { size Day 42 }\end{array}$ & $\begin{array}{c}\% \text { male/female } \\
\text { kits }\end{array}$ \\
\hline Undivided (control) & $85 / 5196(1.6 \%)$ & $55 / 677(8.1 \%)$ & 7.68 & $50.5 / 49.5$ \\
Divided Day 42 & $54 / 5274(1.0 \%)$ & $35 / 684(5.1 \%)$ & 7.71 & $49.9 / 50.1$ \\
& $0.006^{*}$ & $0.03^{*}$ & & \\
\hline
\end{tabular}

*Year is a significant factor (0.04), demonstrating variation among years (2012 and 2013).

Table 4. Categorization of bite type with sex of kits.

\begin{tabular}{cccc}
\hline Type of bite & Male kits & Female kits & Accumulated (\%) \\
\hline Neck bite & $2(6 \%)$ & $32(49 \%)$ & $34(35 \%)$ \\
Ear bite & $21(68 \%)$ & $4(6 \%)$ & $25(26 \%)$ \\
Other bites & $8(26 \%)$ & $29(45 \%)$ & $37(39 \%)$ \\
Accumulated bites pr sex (\%) & $31(32 \%)$ & $65(68 \%)$ & $96(100 \%)$ \\
\hline
\end{tabular}

Table 5. Average body weight in gram ( \pm S.D. $)$ of male and female kits from divided and undivided litters on Days 42 and 56. Mean body weight increase represents mean weight gain between Day 42 and 56 (growth rate).

\begin{tabular}{cccccccc}
\multirow{2}{*}{$\begin{array}{c}\text { Group } \\
\text { Number } \\
\text { of litters }\end{array}$} & \multicolumn{2}{c}{ Body weight Day 42 } & \multicolumn{2}{c}{ Body weight Day 56 } & \multicolumn{2}{c}{$\begin{array}{c}\text { Body weight increase } \\
\text { Day 42 to 56 }\end{array}$} \\
\cline { 3 - 8 } & & Male kits & Female kits & Male kits & Female kits & Male kits & Female kits \\
\hline Undivided (control) & 99 & $334(84) \mathrm{ab}$ & $293(57) \mathrm{b}$ & $748(123) \mathrm{b}$ & $621(76)$ & $412(66) \mathrm{b}$ & 329 \\
Divided with female & 50 & $318(74) \mathrm{b}$ & $298(58) \mathrm{b}$ & $754(111) \mathrm{b}$ & $636(97)$ & $435(50) \mathrm{a}$ & 337 \\
Divided alone & 65 & $355(54) \mathrm{a}$ & $317(42) \mathrm{a}$ & $794(81) \mathrm{a}$ & $648(63)$ & $439(42) \mathrm{a}$ & 331 \\
& & 0.03 & 0.01 & 0.03 & NS & 0.004 & NS \\
\hline
\end{tabular}

Numbers in brackets are standard deviation. Different letters in a row indicate difference between groups at $\mathrm{P}<0.05$. NS $=$ Not significant between groups.

\section{Discussion}

\subsection{Mortality and Bites among Kits in Experimental Groups}

Biting among mink kits starts around Day 42 and increases towards Day 49 of age especially in the large litters and this can be detrimental to animal health and welfare as well as reducing the quality of pelts [7]. Therefore, we have here evaluated a system of partially weaning of the biggest kits from large litters (6 - 9 kits) at 42 days of age in an attempt to reduce biting and improve animal welfare and growth rate. Our findings from two consecutive breeding seasons show that the number of kits exhibiting bites decreases from 85 (1.6\%) for litters not weaned until Day 56, to only $54(1.0 \%)$ for litters partially weaned on Day 42 . The number of litters with kits exhibiting bites, when weaning took place on Day 56, was 55 (8.1\%) compared with only $35(5.1 \%)$ litters when partial weaning occurred on Day 42 (Table 3). These findings agree with those of others [9], who report more biting in large litters when compared with small ones. This indicates that when kits are crowded together, it may induce fighting and biting, as they compete for the available food source. Similarly, crowding of other farm animals has been shown to result in chasing, fighting and biting that reduce growth rates and increase death rates [10] [11].

Of the total number of mink kits bitten in this study, $68 \%$ were females. This agreed with our previous findings, where $80 \%$ and $65 \%$ of the bitten kits were females [3] [5]. Most male kits with bites were bitten in the ear region (ear sucking 68\%), whereas most female kits with bites were bitten in the neck region. Ear suckling was only $6 \%$ for female kits in this study (Table 4). Female kits with bites weighed on average less than their litter sisters ( $\mathrm{P}=$ 0.007), whereas male kits with bites weighed the same as their litter brothers. While it is unknown, what promotes 
biting among mink kits is likely to be for the same reasons as other farm animals [10] [11]. The resultant crowding in large litters leaves little personal space for each kit and similar studies have revealed sex differences in tail biting in pigs, where males are more often bitten than females [12]. Moreover, density, herd size and age have been identified as important risk factors to reduce tail biting in pigs [12].

\subsection{Growth Rates in Experimental Groups}

Growth rates were higher for male kits in both groups of divided litters - both the smallest kits that stayed "with female" and the largest kits that were placed "alone"-compared with the undivided control litters (Table 5). Results could also indicate a suppressed growth rate for male mink kits in large undivided litters from 42 to 56 days of age in the control group compared with partly weaned litters, most likely resulting from competition for feed and access to water. Similar results have been documented from other species, e.g. rabbits and rats, where growth rates are negatively correlated with litter size [13].

This study clearly demonstrates that there is a difference between males and females in the causes of bites and positions of the bites on the body. Furthermore, this study confirms that just being part of a large litter increases the risk of being bitten, and that being the smallest in the litter further increases the risk of being bitten and bullied by larger litter mates in large undivided litters. Although ad libitum feed is available for the kits in the experimental period, it appears that it can be difficult for small females to be allowed to eat in large litters, resulting in reduced growth rates in large undivided litters. As the dam's milk production ceases and kits become dependent on commercial mink feed, it will be expected that the larger litter mates (normally males) will crowd out the smaller animals (usually females) and force them away from the food source. As a result, we recommend that large litters (6 - 9 or more kits) should be partially weaned (divided), removing the biggest kits on Day 42 of age and housing them 4 - 5 kits together. This management practice can reduce biting and ensure animal welfare in this critical period of mink production.

\section{Acknowledgements}

We thank Louise Nordborg for assistance during sampling on the Research Farm and three anonymous reviewers for highly valuable comments on a previous version of the manuscript. The project was supported by funding from Pelsdyrafgiftsfonden and Kopenhagen Fur.

\section{References}

[1] Hansen, S.W. (2007) Danish Order on Fur Animals: Concepts and Experimental Results Related to the Welfare of Mink (In Danish: Pelsdyrbekendtgørelsen: Begreberog Forsøgsresultateri relation tilvelfærd hos mink). Internal Report "Better Conditions for Mink?", DJF, 5, 7-20.

[2] Clausen, T.N. (2011) Causes of Death in Mink Kits from Birth to the End of July. NJF Seminar, Knivsta, 1-2 November 2011, 11-20.

[3] Hansen, M.U., Weiss, V., Clausen, T.N., Mundbjerg, B. and Lassén, M. (2008) Investigations in Causes of Death among Mink Kits from June to October. Fur Breeders Research Center, Holstebro. Annual Report 2007, 99-107.

[4] Clausen, T.N. (2011) Weaning of Standard Type Mink Puppies Day 42, Day 49 and Day 56. Fur Breeders Research Center, Holstebro, Annual Report 2010, 119-121.

[5] Clausen, T.N. and Larsen, P.F. (2012) Impact of Weaning Age on Kit Performance. Xth International Scientific Congress in Fur Animal Production, Copenhagen, 21-24 August 2012, 336-340.

[6] Jeppesen, L.L., Simonsen, T. and Pedersen, V. (2004) Project Welfare in Practice. Fur Breeders Research Center, Holstebro, Annual Report 2003, 35-44.

[7] Clausen, T.N. (2012) Importance of Time of Weaning for Mink Kits, Day 49 or Day 56. Kopenhagen Research, Annual Report 2011, 162-167.

[8] SAS Institute Inc. (1996) SAS ® System for Mixed Models. SAS Institute Inc., Cary, 633 p.

[9] Risager, H.J. (1989) Optimal Nursing Period Reduce Fight among Mink Kits. Danish Fur Breeding, 5, 315-316.

[10] Dawkins, M.S. (1998) Evolution and Animal Welfare. Quarterly Review of Biology, 73, 305-328. http://dx.doi.org/10.1086/420307

[11] Keeling, L. and Gonyou, H. (2001) Social Behaviour in Farm. Animals CAB International, Wallingford. http://dx.doi.org/10.1079/9780851993973.0000 
[12] Sonoda, L.T., Fels, M., Oczak, M., Vranken, E., Ismayilova, G., Guarino, M., et al. (2013) Tail Biting in Pigs-Causes and Management Intervention Strategies to Reduce the Behavioural Disorder. A Review. Berliner und Münchener Tierärztliche Wochenschrift, 126, 104-112.

[13] Rödel, H.G., Prager, G., Stefanski, V., von Holst, D and Hudson, R. (2008) Separating Maternal and Litter-Size Effects on Early Postnatal Growth in Two Species of Altricial Small Mammals. Physiology \& Behavior, 93, 826-834. http://dx.doi.org/10.1016/j.physbeh.2007.11.047 